\section{HP0025 THE INFLUENCE OF HAND FUNCTION ON DAILY ACTIVITIES IN PATIENTS WITH RHEUMATIC DISEASE}

LL Reinseth. Department of Occupational Therapy, University College of Soer-Troendelag, Trondheim, Norway

\subsection{6/annrheumdis-2001.1254}

Summary Part I of this study explores how grip strength and total finger flexion of the hand in patients with rheumatic disease influence the abilities to perform daily activities. The second part of the study examines what kind of hand exercises which give the best results. Part III shows to what extent an improvement of grip strength may improve the performance of daily tasks.

Methods In Part I, the grip strength are tested with a Martin Vigorimeter. The measurement of the total finger flexion is done with a ruler. The level of ability in performing daily activities is measured according to the definitions of "The Assessment of Motor and Process Skills" (AMPS) in 229 in - patients with rheumatic disease. In Part II, 194 patients have carried out a four weeks program of balanced, resistive exercises for the hand with therapeutic putty and was tested for grip strength. 153 patients out of these was tested for total finger flexion. A group of 5 patients have carried out a four weeks program for the hands, of Range of Motion (ROM) - exercises, without any resistance added. In Part III, 13 patients are tested with the Grip Ability Test (The GAT - Test) to see if they have accomplished increased abilities in performing daily activities after four weeks of resistive hand exercises.

Controls 5 in-patients at the same centre, did not attend to the hand exercise groups, but participated in the other exercise programme for all the in-patients (Pool exercises and physical therapy).

Results for Part I The analysis shows significant results both on the connexion between the grip strength and the total finger flexion and the ability to perform daily activities. Grip strength was proved to be a more important factor for performing the tasks of daily living than total finger flexion.

Results Part II Those who carried out hand exercises with therapeutic putty $(n=194)$, accomplished an increase of $27 \%$ in grip strength. Those who also were tested for total finger flexion (n =153), had increased the ROM of the total finger flexion with an average of $14 \%$. Those who only carried out ROM exercises, increased $1 \%$ of grip strength and $11 \%$ in range of motion. The control group, which did not participate in any kind of hand exercise, had increased the grip strength with $1,5 \%$, but had no change in ROM of the hand.

Results Part III The GAT-test (the Grip Ability Test) showed a significant improvement of the level of ability to perform daily activities for those who had increased their grip strength.

\section{SP0149 THE MAR Y SOL PROJECT}

GH Thorén. Board of the Lupus/Sjoegren Disease Group, The Swedish Rheumatism Association, Norrkoeping, Sweden

10.1136/annrheumdis-2001.1255

Many rheumatics benefit from sun, warmth and a combination of individual treatment by a physiotherapist and physical training in groups, whereby mobility is improved and pain decreases. Swedes have consequently looked for treatment abroad. At the south of Tenerife in the Canary Islands is the Swedish rehabilitation centre Vintersol. People with a range of chronic diseases can be treated during a period of four weeks, financed by public funds. The number of participants is unfortunately very restricted.

The Östergötland area has a population of somewhat over 400000 , of which 3000 are members of the local branch of the Rheumatism organisation. A total of around 50 persons are annually granted funding for treatment abroad, of which about 22 are adult rheumatics and six juvenile rheumatics. There is a wide disparity between supply and demand. Patients with rheumatoid arthritis and ankylosing spondylitis are those usually given climate-care. Many diagnoses are consequently not included, but age and general health can also be decisive in the selection process.

The Rheumatism organisation in the region of Oestergötland has together with the County Council (Landstinget) in charge of health care in the region carried out a project where 37 rheumatics participated in a 14 -day rehabilitation programme at Marysol in Tenerife, when health professionals from Vintersol were available. The County Council subsidised the project with 11500 swedish crowns (c. 1300 Euro), a sum which also enabled a specialised rheumatology nurse to travel with the group of patients. The National Health Service also decided that the "season ticket system", where a ceiling for medical care is reached after a total annual cost of 1800 swedish crowns, should apply. The participants all had letters of referral from their doctors.

The purpose has been to determine whether two weeks in a warm climate combined with treatment gives a good and prolonged effect. The results have also been compared regarding different diagnoses. The project has aimed to further cooperation by encouraging the County Council to annually subsidise travel for a number of rheumatics who for various diagnostical, economical, health or other reasons are not allowed or do not have the possibility of climate-care.

Good results were noted even after 14 days. All the participants had increased mobility, less pain and reduced need of analgesics. The social aspect was seen to be particularly important for the single or lonely rheumatics. Financial benefit was noted in the comparison of four weeks at Vintersol at a cost of 40000 Swedish crowns and two weeks at Mar y sol for 10000 Swedish crowns. The relatively low cost was ensured by local volunteerwork, and the participants paid both privately and with help from various funds.

\section{Patient support and education}

\section{HP0029 AN AUDIT OF THE RECORDS OF A RHEUMATOLOGY TELEPHONE HELPLINE}

${ }^{1} \mathrm{JM}$ Mooney, ${ }^{2} \mathrm{~A}$ Brooksby. ${ }^{1}$ Rheumatology Department; ${ }^{2}$ Clinical Audit, Norfolk and Norwich Hospital, Norwich, UK

\subsection{6/annrheumdis-2001.1256}

Background Rheumatology nurse practitioners provide advice, support and information via a telephone helpline. Patients, carers and health professionals access this service. The U. K. C. C. (1998) states that record keeping is an integral component of nursing and should reflect an accurate account of care given.

Objective An audit was undertaken to discover whether the written documentation of the telephone helpline was recorded satisfactorily. 